\title{
PSICOLOGIA E A PRODUÇÃO DO CUIDADO NO CAMPO DO BEM-ESTAR SOCIAL*
}

\author{
João Paulo Macedo e Magda Dimenstein \\ Universidade Federal do Rio Grande do Norte, Natal, Brasil
}

\begin{abstract}
RESUMO: Este trabalho se propõe discutir concepções e práticas de cuidado de psicólogos que atuam no campo das políticas sociais, especificamente no âmbito da Saúde (SUS) e Assistência Social (SUAS) e suas interfaces com os modos de governo e gestão da vida produzidos no contexto biopolítico contemporâneo. O estudo foi realizado em 05 localidades que contam simultaneamente em seu território com Unidades Básicas de Saúde/UBS e Centros de Referência da Assistência Social/CRAS. Acompanhamos o cotidiano e a rotina dos psicólogos que atuam nesses serviços a partir da observação participante e realização de entrevistas. Identificamos que os modos de cuidado produzidos nesses campos pelos profissionais da psicologia indicam tanto uma adesão a um ideal de produzir sujeitos autônomos, produtivos, saudáveis e conscientes dos seus direitos, logo se configurando como práticas normativas, quanto expressam tentativas de ruptura com o estabelecido.
\end{abstract}

PALAVRAS-CHAVE: psicologia; políticas sociais; biopolítica; produção de subjetividade.

\section{PSYCHOLOGY AND PRODUCTION OF CARE IN THE AREA OF SOCIAL WELFARE}

ABSTRACT: The purpose of this study is to discuss the care conceptions and practices of psychologists that work in the area of social policy, specifically in health (Unified Health System) and in social assistance (Unified Social Assistance System), and its interfaces with the modes of government and life management produced in the contemporary bio-political context. The study was accomplished in five localities that have in their territories Basic Health Units and Referral Centers for Social Assistance. Using participant observation and interviews, we accompanied the daily routine of the psychologists that work in these services. We identified that these professionals produced modes of care that indicate an adherence to the ideal production of subjects that are autonomous, productive and healthful, and that are aware of their rights, thereby constituting normative practices that express attempts at rupturing with the establishment.

KEYWORDS: psychology; social policies; biopolicy; production of subjectivity.

\section{Introdução}

A questão do cuidado e da qualidade da atenção prestada nos serviços e/ou programas de contextos comunitários é hoje um ponto central de problematizações e debates desenvolvidos no campo da saúde pública. Por se tratar de uma dimensão não apenas técnica, mas acima de tudo ético-política, pode tanto provocar interferências nas práticas e formas organizativas no trabalho das equipes, dos serviços e da gestão em saúde quanto operar processos de mudança, seja na formação teórico-prática, seja na produção subjetiva desses trabalhadores. Esses são os principais pontos observados nas recentes discussões e proposições em torno das práticas que têm como foco a humanização, o acolhimento e a responsabilização para com o usuário. Além disso, estudos recentes têm indicado a necessidade do desenvolvimento de experiências e projetos na produção de autonomia no cuidado e produção da vida como objetos de aprendizagem e potencialização de "perfis" de trabalho individual e coletivo (Ceccim \& Ferla, 2006; Teixeira, 2005; Barros, 2005). Deste modo, pretendemos, com este trabalho, na esteira das discussões que tomam o cuidado como uma ferramenta conceitual de ordem ontológica, genealógica e crítica na reconstrução das práticas em saúde (Ayres, 2004), analisar as concepções e práticas de cuidado desenvolvidas pelos psicólogos que atuam no campo das políticas sociais, especialmente no âmbito da Saúde Pública (SUS) e Assistência Social (SUAS).

É importante ressaltar que o nosso interesse por essa temática não está centrado no aspecto técnico da questão, ou seja, no modo como os profissionais da psicologia estão atuando no campo do Bem-Estar, pois entendemos que o cuidado, como bem ressaltou Ayres (2004), não é somente um "conjunto de procedimentos tecnicamente orientados para o bom êxito de um certo tratamento" (p. 74). Nesse sentido, queremos proble- 
matizar a hipervalorização da técnica em detrimento de uma atuação pautada por uma compreensão e/ou atitude ético-política, cada vez mais frequente na psicologia (Barros, 2005; Dimenstein, 2006). Para tanto, pretendemos discutir os modos de cuidado produzidos por esses psicólogos no campo das políticas sociais, tendo como elemento analítico as problematizações foucaultianas sobre os modos de governo e gestão da vida produzidos no contexto biopolítico contemporâneo.

Michel Foucault (2008), em seu debate sobre o biopoder, regime político que configura a vida como objeto, nos coloca que tanto a vida quanto a subjetividade foram tomadas de "assalto" na atualidade. No que se refere ao campo social, tal dimensão tem sido um território profícuo de investimento de práticas governamentais, através de mecanismos de regulação e controle das populações, ou seja, gestão e governo de condutas e subjetividades. Portanto, fabricação de mundos e modos de vida, especialmente para a população margeada de direitos e garantias sociais.

Nesse sentido, temos o interesse de refletir como a psicologia vem operando no campo das políticas sociais como uma ferramenta biopolítica, cujo um dos efeitos é a dominação, a disciplina e a docilização dos corpos e da vida. Entretanto, também buscamos neste estudo considerar como os psicólogos que atuam nesses espaços têm investido na produção de resistência e diferença, ou seja, de que forma estão potencializando a vitalidade social e as forças inventivas nesses coletivos.

\section{Estratégias metodológicas}

Delimitamos quatro localidades diferentes do município de Natal que dispunham no seu território tanto de UBS quanto de CRAS, totalizando oito serviços, dois em cada localidade (quatro Unidades Básicas de Saúde/ UBS e quatro Centros de Referência da Assistência Social/CRAS). Nosso critério de escolha foi pautado na perspectiva da intersetorialidade das políticas de saúde e assistência social, tendo como norte a articulação em rede entre os seus serviços de base comunitária.

As visitas tiveram o intuito de conhecer o funcionamento dos serviços, o cotidiano dos técnicos, especialmente dos profissionais da psicologia e as práticas por eles desenvolvidas. Além disso, conhecemos a realidade social em que os psicólogos atuavam, por meio da observação participante e do uso de entrevistas abertas. Inicialmente foram entrevistados 10 profissionais, sendo oito psicólogos da Assistência Social (CRAS) - dois em cada Centro de referência - e dois da Saúde (UBS). Sobre os psicólogos das UBS, é importante esclarecer que só foi possível entrevistar dois profissionais pelo fato de que em duas das quatro UBS visitadas o profissional estava afastado por licença saúde. Após a realização dessas visitas, constatamos, através dos técnicos entrevistados, a existência de mais uma UBS e um CRAS, ambos localizados em regiões próximas, que também desenvolviam constantes articulações entre si, inclusive formando novos pontos de rede com os serviços por nós pesquisados.

Em função disso, incluímos no nosso campo de pesquisa esses dois outros serviços, totalizando cinco UBS e cinco CRAS visitados, consequentemente, 13 psicólogos entrevistados (três psicólogos de UBS's e 10 dos CRAS's).

De um modo geral, nos relatos desses técnicos figuraram não só a descrição da rotina e das atividades desenvolvidas no serviço, mas também as experiências e/ou situações que marcaram de forma singular suas atuações na comunidade.

\section{A psicologia e a produção do cuidado no nível básico da saúde e assistência social}

A partir dos elementos levantados nas observações e nas entrevistas identificamos duas formas de perceberem a produção de cuidado em seus campos de atuação: (a) na primeira, presente na maioria das entrevistas $(n=10)$, o cuidado é visto como uma forma de intervenção especializada que objetiva ajudar ou melhorar a vida das pessoas, tornando-as autônomas, produtivas, autossustentáveis, saudáveis e conscientes dos seus direitos; (b) a segunda, posta por uma minoria dos técnicos entrevistados $(n=03)$, compreendia o cuidado como um campo de possibilidades, onde as pessoas poderiam experienciar e viver a partir de suas diferenças, independente das expectativas esperadas por cada política ou pelo próprio serviço ${ }^{\mathrm{I}}$.

Nesse sentido, percebemos, a partir das narrativas dos técnicos, o entendimento da produção de cuidado tanto no seu sentido técnico quanto como postura acolhedora, a partir de um exercício éticopolítico. Ou seja, para a maioria, a ação de cuidado era tratada como uma atividade ou procedimento que tem a função de monitorar as necessidades de saúde e/ou necessidades sociais dos usuários, além da realização de tratamentos e/ou acompanhamentos propostos pela equipe do serviço. Já para pequena parte dos técnicos, a ação de cuidado era tida como uma atitude ou postura que encontra no exercício de reflexão crítica a produção de práticas promotoras não só de mudanças e transformações no modo desses profissionais atuarem no serviço, mas também nas suas relações de trabalho e territórios subjetivos (Ayres, 2004).

Destacando esse primeiro entendimento sobre o cuidado como monitoramento ou apenas como atenção vigilante ao bem-estar do usuário, somente a partir das dimensões biomédica e sanitária, como bem colocou 
Ayres (2004), os relatos dos técnicos $(\mathrm{n}=10)$ apontaram para o fato das comunidades estarem cada vez mais perdendo o seu poder mobilizador e reinvidicatório frente às problemáticas sociais que enfrentam. Ou seja, para esses técnicos, a maior parte dos usuários não está comprometida com os problemas e questões comuns do cotidiano da sua localidade.

Sobre isso, um ponto recorrente nos relatos foi a ênfase no pouco envolvimento dos moradores no tocante aos problemas de infraestrutura de seu bairro: condições das casas, algumas de taipa, outras sem banheiros; condições das ruas, muitas sem pavimentação ou sistema de esgoto, que no período chuvoso ficam inacessíveis para o trânsito em virtude das grandes poças de lama e do acúmulo de lixo e outros dejetos; a pouca quantidade de áreas para o lazer ou práticas esportivas, culturais e recreativas, restando, portanto, os bares como reduto para a diversão ou lazer; a não manutenção das praças públicas e iluminação pública, além de problemas quanto à coleta regular do lixo; a ineficiência de alguns equipamentos sociais, como a demora para a realização de consultas e exames médicos, a falta de vagas nas escolas ou mesmo a falta de segurança pública.

Para esses técnicos, o problema quanto à falta de comprometimento dos usuários não se configura somente em termos da pouca mobilização coletiva para a reivindicação de melhorias estruturais ou pela instalação de equipamentos urbanos e sociais nas localidades que residem. Mas, também, por não se responsabilizarem em relação à educação dos filhos e à manutenção da saúde de si próprios e de seus familiares (crianças, adolescentes e idosos); ou então por não reivindicarem seus direitos e procederem na denúncia de possíveis ilegalidades (ou irregularidades) quanto aos benefícios dos programas sociais.

A falta de informação (ou consciência) da população-usuária frente à realidade em que vivem explicita para esses técnicos a questão da educação como um dos grandes vilões dessas comunidades. Entendem que o desenvolvimento de ações em educação em saúde ou na mobilização e participação popular se configura como uma de suas principais atividades nesse campo. Investem em ações para que esses usuários possam cuidar melhor (ou de uma forma mais orientada) de si e dos outros, em diferentes aspectos: higiene pessoal e bucal, manuseio de alimentos e verificação da questão nutricional, manuseio do lixo, prevenção de doenças sexualmente transmissíveis e o planejamento familiar, compreendendo melhor sobre os riscos e dificuldades que a situação de uma gravidez indesejada pode provocar, além de outras questões como o consumo de drogas, violência, negligência no cuidado com os filhos e a questão dos direitos e benefícios sociais.
No tocante às atividades que desenvolvem, a maioria dos profissionais entende que o fato de estarem inseridos na realidade dos usuários, ou seja, na rotina da comunidade e de suas casas, isso, por si só, já se configura como um grande facilitador para que possam ajudar de uma maneira mais pontual tais famílias. Pois assim, podem orientar de uma forma mais próxima e efetiva quanto à forma de procederam, definindo atitudes e/ou comportamentos que minimizem conflitos familiares e/ou sociais, ou ainda, possíveis inabilidades frente à realidade socioeconômica em que se encontram.

Sobre o papel das políticas sociais (saúde e assistência) frente às realidades em que atuam, os técnicos as consideram bastante válidas, pois entendem que são ações governamentais que levam possibilidades concretas para essas comunidades, disponibilizando maior acesso a uma gama de serviços que visam melhorar as condições pessoais e sociais da população, principalmente, a partir da garantia de direitos e de cidadania.

Imbuídos dessa perspectiva, as ações desenvolvidas pelos psicólogos nesse contexto partem, quase sempre, de um projeto de vida já previamente definido - por eles próprios (ou da leitura que fazem dos documentos norteadores da política) - para a população-usuária dos serviços. Com isso, tais profissionais esperam encontrar, através dos resultados das intervenções das políticas de saúde e da assistência social, uma população minimamente sadia, limpa, ocupada, organizada e sem conflitos.

No tocante ao modo como os entrevistados operam suas práticas no serviço, a partir da produção do cuidado, eles focam suas atividades considerando os procedimentos estruturados pela rotina de atendimento do serviço: realização da escuta e encaminhamento para a realização de atividades (participação de grupos informacionais e/ou pedagógicos; realização de visita domiciliar e/ou atendimento no próprio serviço, encaminhamentos para a rede de saúde ou para rede socioassistencial). O que indica que tais profissionais compreendem e lançam mão da ideia de cuidado, muito mais, a partir de um enfoque (estritamente) instrumental do que de uma compreensão dos usuários ou da própria comunidade como também coparticipantes da produção de saúde. Sobre isso, Ayres (2004, p. 84) argumenta que

A ciência produz o conhecimento sobre as doenças ou sobre problemas sociais [grifos nossos], a tecnologia transforma esse conhecimento em saberes e instrumentos para a intervenção, os profissionais aplicam esses saberes e instrumentos e produz-se a saúde. Precisamos considerar que a direção inversa também é verdadeira: que o modo como aplicamos e construímos tecnologias e conhecimentos científicos determina limites para o que podemos enxergar como necessidades de intervenção em saúde. 
Nesse sentido, o autor ainda adverte que

Precisamos ter claro também que nem tudo que é importante para o bem estar pode ser imediatamente traduzido e operado como conhecimento técnico. E por fim, mas fundamental, precisamos estar atentos para o fato de que nunca, quando assistimos à saúde de outras pessoas ou demais necessidades sociais [grifos nossos], mesmo estando na condição de profissionais, nossa presença na frente do outro se resume ao papel de simples aplicador de conhecimentos (Ayres, 2004, p. 84).

Desse modo, consideramos, a partir de Ayres $(2001,2004)$, que a tecnologia e/ou o saber instrumental não se restringem a um modo de fazer ou de organizar o serviço para a aplicação da ciência através da técnica, mas devemos entendê-los (tanto a tecnologia quanto o saber instrumental) como um processo em que é possível atuar a partir deles em termos mediacionais, e não somente de forma unilateral e hierárquica.

Para esse autor, podemos não só escolher o que o público deva ser ou fazer, reforçando a tradicional forma de atuar no campo das políticas sociais, com a redução de sujeitos a objetos e assim manipulá-los, mas, também, produzir uma maior participação do usuário (e da comunidade) a partir de sua sabedoria prática, dos seus saberes cotidianos, para gerar recursos e encontrar melhores ações para responder as suas necessidades de saúde ou de segurança social (Ayres, 2001, 2004).

Nesse sentido, Ayres (2004) ainda endossa que, "nada, nem ninguém, pode subtrair a esse mesmo indivíduo, como aspirante ao bem-estar, a palavra última sobre suas necessidades ... é preciso que o cuidado em saúde considere e participe da construção de projetos humanos" (p. 84). Portanto, atuar no campo das políticas sociais, priorizando a questão da produção do cuidado somente a partir do saber técnico, possibilita prioritariamente o exercício da tutela e da desapropriação do saber do outro sobre si próprio na condução do cuidado e dos seus projetos de futuro. Favorece, igualmente, a criação de mecanismos de regulação e vigilância da vida, o que torna as políticas do bem-estar um território profícuo para o exercício da gestão ou do governo da população, através da disciplina e do controle, como estratégias biopolíticas para se fundar ou redimensionar a ordem social vigente (Foucault, 2005, 2008).

$\mathrm{O}$ que na verdade queremos alertar, conforme aponta Foucault (2004), no texto "Um sistema finito diante de um questionamento infinito [1983]", é que, apesar dos efeitos positivos do Sistema de Seguridade Social (que no Brasil é composto pela saúde, assistência social e previdência), tal sistema também comporta "efeitos perversos", pois sua crescente rigidez burocrática, condição transferida para o cotidiano dos serviços, acaba fomentando situações de dependência, controle e infantilização da população mais do que efetivamente viabilizando ações que busquem a autonomia da população ou dos mais variados grupos sociais que são diretamente (ou potencialmente) beneficiados com tais políticas.

Com isso, não queremos menosprezar uma história de luta política da sociedade civil organizada de propor políticas sociais que resultem não só na melhoria das condições de vida de todos, mas, principalmente, em articulações necessárias para o estabelecimento de novas relações de poder. Queremos chamar atenção para o fato de que o campo dos direitos sociais foi afirmado no Brasil, desde o seu início, a partir de estratégias que tinham como propósito vingar os objetivos civilizatórios da República, principalmente a partir da coalizão histórica entre Saúde, Ordem e Progresso. Como bem definiu Baptista (1999): "Saúde e Ordem têm a mesma face, Ordem e Progresso têm a mesma bandeira" (p. 25).

Considerando o atual ordenamento jurídico-político que foi conceituado por Foucault $(2000,2005,2008)$ como biopolítica e via por excelência em que o capital recorre para tomar a vida "de ponta a ponta", como nos informa Pelbart (2003), tal tecnologia combinou as técnicas disciplinares (adestramento do indivíduo, aumento de suas aptidões e extorsão de suas forças, etc.) com os dispositivos de regulação e controle da população (proliferação, nascimentos e mortalidades, nível de saúde, expectativa de vida, etc.).

No contexto das políticas sociais no Brasil, principalmente no tocante ao nível básico de atenção, Merhy e Franco (2006) discutem a ênfase que é dada ao padrão tecno-assistencial e a utilização de instrumentos clássicos de educação sanitária em massa e o controle de endemias com um enfoque epidemiológico estritamente centrado na doença. $\mathrm{O}$ resultado disso é que as atividades desenvolvidas no serviço ficam fortemente orientadas por esse padrão epidemiológico e/ou social das famílias, o que acaba muitas vezes desconsiderando as singularidades dos usuários e da comunidade, produzindo a coisificação do cuidado e a biologização dos problemas sociais, a partir da leitura desses problemas pelo controle, pela disciplina e pela regulação da população. Com isso, restam como "tratamento" intervenções que visam modular o comportamento das pessoas, ou seja, as atitudes, pensamentos, modos de sentir e de se relacionar consigo e com outro, no objetivo de "controlar" as incertezas e os riscos do mundo contemporâneo (adoecimento, velhice, desemprego, violência, criminalidade, tráfico, etc.) a partir de práticas pedagógicas e pela medicalização.

O tipo de sujeição a que esses moradores são submetidos acaba tornando-os não só produtivos e dóceis, 
mas também promove uma mudança em seus modos de ser e o investimento de seu desejo em modelos homogeneizantes e privatizantes da vida. É o que podemos visualizar, por exemplo, quanto às articulações que acontecem entre as UBS's e CRAS's (ou nas articulações desses serviços com os demais equipamentos de outras políticas: segurança alimentar, educação, ações de geração de renda, etc.). Tais articulações acontecem muito mais como uma forma de ampliar a vigilância e a regulação da população do que efetivamente viabilizar cuidados em relação à comunidade e os usuários.

Ao considerarmos as famílias que são beneficiárias do programa bolsa família no tocante ao compromisso que têm de manter a frequência regular das crianças na escola e o acompanhamento regular de sua saúde, uma das funções dos técnicos do CRAS era exatamente acompanhar aquelas que não estavam cumprindo tais prerrogativas. É comum procederem com o artifício de ameaçar as famílias com a perda do benefício caso não mudem seus comportamentos de negligência ou de falta de responsabilização sobre a saúde e a educação dos filhos. Dessa forma, as articulações propostas pelos CRAS com agentes comunitários de saúde são no intuito realizar ações de vigilância e fiscalização das famílias, para o cumprimento das contrapartidas ou sobre o encaminhamento de denúncias e irregularidades, mais do que para viabilizar ações de cuidado em saúde e promoção de direitos.

No tocante às articulações entre os CRAS e demais políticas, a exemplo de ações no campo de projetos de geração de renda e/ou oferta de cursos profissionalizantes como de secretariado, informática, relações humanas, dentre outros, a preocupação era a afirmação do discurso já massificado sobre a necessidade de qualificação para uma melhor oportunidade de emprego, apesar de, em nenhum momento, se discutir nesses grupos sobre as possibilidades/dificuldades do mercado local, sobre questões quanto à empregabilidade nessas regiões, ou mesmo sobre se pensar propostas ou outras atividades para geração de emprego/renda que promovessem a sustentabilidade das famílias como projetos de economia solidária.

Especificamente na articulação CRAS/UBS, observamos que algumas ações entre esses equipamentos tinham somente o propósito de estabelecer uma "dobradinha" ou uma "ponte" entre os atendimentos dos serviços: médico, psicológico e o serviço social. Tais articulações aconteciam no intuito de estabelecer encaminhamentos dos usuários que frequentam o CRAS para serem atendidos na UBS e vice-versa. O sentido da articulação era a viabilização de benefícios sociais ou marcação mais rápida de consultas e/ou exames nos serviços especializados de saúde mental (ambulatório, CAPS e Hospital Psiquiátrico).
Nesse sentido, é importante sublinhar, a partir de Merhy e Franco (2006), que a potencialidade das ações da atenção básica (e por extensão também podemos pensar a proteção social básica - CRAS) reside tanto nos princípios que norteiam os processos de trabalho dos profissionais (integralidade, resolutividade, intersetorialidade das ações, vínculo, corresponsabilidades e estímulo à participação social) quanto na reorganização dos serviços e das práticas a partir desses princípios e das necessidades da população atendida. Em contrapartida, um dos grandes entraves para dar seguimento e avançar nesses campos, conforme assinalam esses autores, é o fato dos profissionais que atuam no campo das políticas sociais ainda terem uma formação hegemonicamente pautada pelo paradigma biomédico, cujo foco é a doença e a execução de procedimentos pautados pelo saber técnico, além de uma visão linear do processo saúde-adoecimento. Não muito diferente disso está a psicologia, tendo em vista ter sido configurada por uma formação profundamente tecnicista e carente de crítica (Dimenstein, 2000, 2006).

Para Ayres (2001), modelos de formação acríticos são na verdade causadores de um dos maiores entraves da política de saúde (e das demais políticas), considerando a dificuldade que os trabalhadores têm de conjugar novas abordagens à saúde e proteção da população, em função de uma formação/atuação que se encerra na racionalidade médica, e por saberes padronizantes e aprisionadores de subjetividades.

\section{A produção do cuidado como produção de diferença}

Dentre as narrativas e as experiências relatadas por um número bem menor de profissionais $(n=3)$, percebemos outros posicionamentos frente às práticas de cuidado por eles desenvolvidas. Ou seja, eram formas de atuação que se aproximavam muito mais da proposta anteriormente discutida por Ayres (2004), Merhy (2002) e Teixeira (2005), a partir de um tipo de investimento que os distanciava de ações vigilantes ou de controle.

Tal postura possibilitava a esses técnicos experimentar ações que permitiam tanto à população quanto a si próprios viverem suas diferenças. Vale ressaltar que só foi possível visualizar tais ações em uma das cinco bases territoriais que visitamos na realização deste estudo. Nessa localidade, tanto a UBS quanto o CRAS estavam organizados a partir de ações mais integralizadas dentro e fora dos limites territoriais de sua área adstrita, o que os possibilitava, vez ou outra, acionar de maneira resolutiva redes de cuidado com outros serviços e equipamentos comunitários. 
Tal postura, na opinião dos profissionais entrevistados, proporcionou tanto uma escuta mais diferenciada para as questões trazidas pelos usuários quanto o acolhimento dessa diferença pela própria equipe técnica. $\mathrm{Ou}$ seja, a forma como esses técnicos procediam no encontro com esses usuários era da ordem da valorização de um maior espaço de participação, envolvimento e compromisso na produção de redes de cuidado, seja no próprio serviço, seja na própria localidade, através do fortalecimento dos vínculos comunitários.

Para esses profissionais, trabalhar em comunidade implica sempre trabalhar articulados com outros profissionais e estabelecimentos (seja da saúde, da assistência social e demais políticas) para que o exercício de atenção e cuidado, da corresponsabilização dos serviços, possa acontecer.

A articulação UBS/CRAS se dava em função das reuniões em conjunto entre os profissionais do PSF e, principalmente, dos ACS com os técnicos do CRAS, ora em um serviço, ora em outro, visando à realização de eventos/atividades ligados à rotina de trabalho específico de cada política: campanhas de vacinação, datas comemorativas no âmbito da saúde, datas comemorativas frente a lutas e bandeiras sociais e na defesa de direitos. Muitas dessas reuniões tinham como foco o planejamento das atividades em conjunto UBS/CRAS voltadas para o grupo de idosos ou demais atividades que ocorriam na comunidade.

A articulação entre os psicólogos da UBS e do CRAS se dava com a parceria do trabalho em conjunto com os grupos, no sentido de atenderem as ações e objetivos específicos de cada serviço. Para melhor esclarecer a integração entre os profissionais dos dois serviços, detalharemos a seguir as atividades desenvolvidas com o grupo de idosos na comunidade.

O grupo de idosos surgiu como uma forma de organizar as atividades da UBS voltadas para o público considerado de terceira idade. Inicialmente seu propósito era preventivo e tinha como principal foco o acompanhamento da saúde desse segmento da população através do controle da hipertensão e diabetes, a partir de atividades informativas e procedimentos de aferições dos índices de saúde e distribuição de medicamentos. Ou seja, era um tipo de cuidado reduzido a questões biomédicas. Com o passar do tempo e uma maior integração dos profissionais envolvidos (médicos, enfermeiros, agentes comunitários de saúde, psicólogo, etc.) com a própria população usuária, no sentido de priorizar a escuta de seus interesses, projetos de vida e necessidades, os encontros passaram a ter o aspecto de um "grupo de convivência". Além de a equipe técnica realizar as atividades concernentes aos cuidados específicos em saúde (informações, aferições e medicação), também ocorriam atividades com enfoque para o lazer, práticas de atividade física e valorização da cultura local, com a realização de trabalhos em renda e a dança do pastoril (cultura folclórica da região).

Sob esse aspecto, o psicólogo da UBS referiu que o serviço acabou se reconfigurando, passando de um espaço somente destinado ao "tratamento de doenças" para ser o lócus de outras relações com a comunidade. Ou seja, se inicialmente os participantes do grupo de idosos se dirigiam ao serviço com muita resistência para fazer seu acompanhamento de saúde, hoje, os mesmos usuários têm a UBS como uma espécie de centro de convivência, lugar de encontro, onde não só compartilham histórias, experiências e solidarizam-se uns com os outros através do apoio afetivo, mas também desenvolvem articulações de mobilização política, no sentido de reivindicarem melhorias e apoio, seja para o grupo (na manutenção dos ensaios e viabilização das apresentações em eventos culturais do município), seja para a própria comunidade.

Sobre as atividades culturais desenvolvidas no grupo de idosos, o psicólogo da UBS ainda ressalta que, além dos usuários, também participam alguns ACS que têm um forte envolvimento afetivo e social, de modo que o grupo apresenta-se como um potente canal para o exercício do cuidado de si enquanto trabalhadores da saúde. Já os profissionais dos CRAS também se integraram às atividades desenvolvidas nesse grupo de idosos, no objetivo de mobilizarem nesse público o debate sobre as formas de envelhecimento na atualidade, na perspectiva dos direitos, benefícios, assim como discutindo questões quanto aos projetos de vida dos participantes do grupo, através de temas como família, solidão, trabalho, lazer, sexualidade.

No tocante ao trabalho desses serviços em termos de intervenções na comunidade, as técnicas do centro de referência perceberam que os moradores dessa localidade eram grandes "colecionadores" de certificados dos mais variados cursos ofertados por entidades profissionalizantes em parceria com o CRAS. Desse modo, iniciaram uma discussão sobre o fato desses cursos não gerarem renda para a população e da necessidade de avaliação dos resultados ou impacto disso na comunidade. Nesse sentido, propuseram inserir na rotina desses cursos o debate sobre possibilidades de emprego e renda, associativismo, ou mesmo programar cursos com propostas para geração de renda tendo a autossustentabilidade como foco (reciclagem, artesanato, plantio em hortas, dentre outros). Nessa mesma direção, intervieram no grupo de crianças, cujas atividades ficavam restritas às ações de recreação, com o uso de alguns poucos brinquedos e a transmissão de programas infantis pela televisão. Com a reestruturação do grupo, passou a funcionar com atividades com enfoque na educação ambiental e o desenvolvimento de 
sociabilidades, com o resgate de valores no tocante ao respeito e o cuidado para com o outro, cujo resultado foi o estreitamento das relações do CRAS com a escola da comunidade.

Em outro CRAS, também visualizamos um conjunto de ações bastante inovadoras e que vale a pena ser assinalado: trata do trabalho desenvolvido pelo grupo de mulheres com a criação de uma horta comunitária como possibilidade de geração de renda e o desenvolvimento de experiências a partir da autogestão. Esse grupo ainda conta com uma assessoria técnica da prefeitura municipal sobre o processo de adubação e manuseio de verduras, hortaliças e ervas medicinal. Além disso, o grupo ainda planeja estabelecer parceria com demais órgãos, a exemplo do SEBRAE, para fortalecer aspectos do associativismo como forma de unir esforços e possibilidades de renda. Paralelo a isso, as técnicas do CRAS trabalham aspectos no grupo quanto às dificuldades comuns que as mulheres enfrentam (cuidado com os filhos, relação com os maridos, mercado profissional, dentre outros), construindo assim uma rede de apoio afetiva e social entre as participantes.

\section{Considerações finais}

Ao longo deste trabalho, pontuamos as concepções e práticas de cuidado de psicólogos que atuam no âmbito da Saúde (SUS) e Assistência Social (SUAS). Isso nos possibilitou visualizar duas ordens distintas de concepções: a que toma o cuidado como uma forma de intervenção especializada, conformado por um tipo de saber instrumental, que coloca o profissional numa posição de hierarquia e definidora de rotinas entendidas como a melhor forma de condução do cuidado para com o outro; e outra que trata do cuidado como práticas que se apoiam no exercício da reflexão sensível, da postura acolhedora e da responsabilização para com o outro, produzidas a partir de um exercício ético-político do próprio encontro equipe-serviço-comunidade.

Considerando essa dupla compreensão sobre o cuidado e seus efeitos descritos ao longo deste trabalho, entendemos a necessidade de que nesses espaços de produção de saúde e de direitos os profissionais da psicologia possam estar mais sensíveis para ações que promovam e potencializem situações de encontro entre usuários, técnicos e moradores. Nesse sentido, possam se organizar e pensar sobre as questões ou problemas que lhes são comuns, pois é isso que tem produzido a diferença no cotidiano. Isso quer dizer que têm recorrido muito pouco às formas individualizantes ou privatizantes usualmente presente nesses espaços de trabalho da psicologia e que indicam modos de atuar que rompem com formas previamente fixadas (valores, identidades, etc.).
A partir desse estudo, podemos pensar elementos que afirmam estratégias de ação no campo da produção do cuidado, da saúde e da cidadania, em que é possível operar em nosso cotidiano profissional por meio de ações que podem não só nos desviar do previamente estabelecido, mas que também nos possibilitam fazer um deslocamento em relação às redes dominantes de poder (Pelbart, 2003).

\section{Notas}

* Agência de Fomento: Conselho Nacional de Desenvolvimento Científico e Tecnológico, CNPq, Brasil.

1 Tais expectativas tratam do cumprimento das metas e índices específicos das condições de saúde e condições sociais empreendidos pelas ações programadas e/ou desenvolvidas por esses serviços nessas localidades

\section{Referências bibliográficas}

Ayres, J. R. C. M. (2001). Sujeito, intersubjetividade e práticas de saúde. Ciência \& Saúde Coletiva, 7(1), 63-72.

Ayres, J. R. C. M. (2004). Cuidado e reconstrução das práticas de saúde. Interface: Comunicação, Saúde e Educação, 8(14), 73-92.

Baptista, L. A. S. (1999). A cidade dos sábios: reflexões sobre a dinâmica social nas grandes cidades. São Paulo: Summus.

Barros, R. D. B. (2005). A Psicologia e o Sistema Único de Saúde: quais interfaces? Psicologia \& Sociedade, 17(2), 21-25.

Ceccim, R. B. \& Ferla, A. A. (2006). Linha de cuidado: a imagem da mandala na gestão em rede de práticas cuidadoras para uma outra educação dos profissionais em saúde. In R. Pinheiro \& R. A. de Mattos (Orgs.), Gestão em redes: práticas de avaliação, formação e participação em saúde (pp. 165-184). Rio de Janeiro: Editora da ABRASCO.

Dimenstein, M. (2000). A cultura profissional do psicólogo e o ideário individualista: implicações para a prática no campo da assistência pública à saúde. Estudos de Psicologia, 5(1), 95-121.

Dimenstein, M. (2006). A prática dos psicólogos no Sistema Único de Saúde/SUS. In Conselho Federal de Psicologia (CFP), I Fórum Nacional de Psicologia e Saúde Pública: contribuições técnicas e políticas para avançar o SUS (pp.8-16). Brasília, DF: Autor.

Foucault, M. (2000). Em defesa da sociedade. Curso no Collège de France (1975 - 1976). São Paulo: Martins Fontes.

Foucault, M. (2004). Ditos e escritos V-Ética, sexualidade e política. Rio de Janeiro: Forense Universitária.

Foucault, M. (2005). A verdade e as formas jurídicas ( $3^{\mathrm{a}}$ ed.). Rio de Janeiro: Nau Editora.

Foucault, M. (2008). O nascimento da biopolítica. Curso no Collège de France $(1978$ - 1979). São Paulo: Martins Fontes.

Merhy, E. E. (2002). Saúde - a cartografia do trabalho vivo. São Paulo: Hucitec.

Merhy, E. E. \& Franco, T. B. (2006). Programa de saúde da família (PSF): contradições de um programa destinado à mudança do modelo tecnoasssistencial. In E. E. Merhy, H. M. Magalhães Junior, T. B. Franco, J. Rimoli, \& W. S. Bueno. 
O trabalho em saúde: olhando e experianciando o SUS no cotidiano ( $3^{\mathrm{a}}$ ed., pp. 55-133). São Paulo: Hucitec.

Pelbart, P. P. (2003). Vida capital: ensaios de biopolitica. São Paulo: Iluminuras.

Teixeira, R. R. (2005). Humanização e atenção primária à saúde. Ciência \& Saúde Coletiva [online], 10(3). Acesso em 20 de setembro, 2008, em http://www.scielo.br/scielo.php?script=sci arttext\&pid=S1413-81232005000300016\&lng=pt\&nrm=iso

João Paulo Macedo é Psicólogo, Mestre em Psicologia pela Universidade Federal do Rio Grande do Norte e Doutorando em Psicologia Social pelo Programa Integrado de Doutorado da Universidade Federal da Paraíba e Universidade Federal do Rio Grande do Norte. Endereço para correspondência: Av. Ayrton Senna, 16/24, Capim Macio. CEP 59080-100, Natal/RN. Email: macedo_jp@yahoo.com.br
Magda Dimenstein é Psicóloga, Doutora em Saúde Mental pelo Instituto de Psiquiatria da Universidade Federal do Rio de Janeiro e Docente do Programa de Pós-Graduação em Psicologia da Universidade Federal do Rio Grande do Norte. Endereço para correspondência: UFRN - CCHLA, Depto. de Psicologia, Campus Universitário Lagoa Nova.

CEP 59078-970. Natal/RN.

Email: magda@ufrnet.br

Psicologia e a produção do cuidado no campo do bem-estar social

João Paulo Macedo e Magda Dimenstein

Recebido em: 24/09/2008

Revisão em: 26/11/2008

Aceite final em: 06/09/2009 